\title{
Measuring the Performance of Primary Healthcare: Existing Capacity and Potential Information to Support Population-Based Analyses
}

\begin{abstract}
Mesure du rendement en matière de soins de santé primaires : capacité actuelle et information potentielle pour les analyses fondées sur la population
\end{abstract}

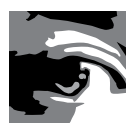

by ANNE-MARIE BROEMELING, PHD

Director, Information Support and Research

Interior Health Authority

Kelowna, BC

Centre for Health Services and Policy Research

University of British Columbia

Vancouver, BC

DIANE E. WATSON, MBA, PHD

Centre for Health Services and Policy Research

University of British Columbia

Vancouver, BC 
Anne-Marie Broemeling et al.

CHARLYN BLACK, MD, SCD

Centre for Health Services and Policy Research

University of British Columbia

Vancouver, BC

SABRINA T. WONG, RN, PHD

Assistant Professor, School of Nursing Culture, Gender and Health Research Unit

Centre for Health Services and Policy Research

University of British Columbia

Vancouver, BC

\section{Abstract}

What did we do? We reviewed the degree to which existing population-based data in Canada can be used to describe and report on primary healthcare ( $\mathrm{PHC}$ ) performance. We identified gaps in current data sources and made recommendations on how these gaps might be addressed to support quality improvement and public reporting for PHC.

What did we learn? Population-based survey and administrative data are available to describe population characteristics and other contextual factors for PHC, as well as some aspects of the material, financial and human resources inputs, and selected activities and decisions at the policy, management and clinical levels. Existing data can also be used to describe some volumes and types of PHC outputs. However, we currently have limited population-based data to assess selected qualities of PHC services (e.g., coordination and interpersonal effectiveness) and most immediate outcomes of PHC. The ability to link data to assess outcomes and attribute changes in outcomes to PHC is limited. A full report describing more than 130 indicators from existing data sources and gaps in current data is available at www.chspr.ubc.ca.

What are the implications? As we look to the future, there is a clear need to build on existing data sources to expand PHC data capacity in Canada. Data are needed to inform an understanding of PHC outputs, outcomes and the linkages among PHC dimensions. Commitment to a comprehensive PHC data collection strategy and information system is needed across Canadian provinces and territories to inform policy development and planning, to evaluate $\mathrm{PHC}$ redesign initiatives and to meet the accountability expectations of Canadians. 


\section{Résumé}

Ce que nous avons fait: Nous avons examiné à quel point les données démographiques actuelles peuvent être employées pour faire un compte rendu du rendement des soins de santé primaires (SSP). Nous avons décelé des lacunes dans les sources actuelles de données et nous avons fait des recommandations afin de traiter ces lacunes, dans le but de favoriser une amélioration de la qualité et de la diffusion publique d'information en matière de SSP.

Ce que nous avons appris: Il existe des données administratives ou issues de sondages auprès de la population qui peuvent servir à décrire les caractéristiques de la population ou d'autres facteurs contextuels pertinents aux SSP, de même que certains aspects touchant aux intrants en matière de ressources matérielles, financières et humaines, et certaines activités ou décisions aux niveaux politique, clinique ou de gestion. Les données disponibles peuvent également servir à décrire certains types et volumes d'extrants dans les SSP. Toutefois, il existe actuellement peu de données de nature démographique qui permettent d'évaluer les critères de qualité en matière de services de SSP (par exemple, la coordination et l'efficacité interpersonnelle) ou encore les résultats immédiats pour les SSP. La possibilité d'associer les données pour évaluer les résultats et les changements connexes est également limitée. Un rapport détaillé décrivant plus de 130 indicateurs à partir des sources de données actuelles, et présentant les lacunes dans les données, est disponible sur le site www.chspr.ubc.ca.

Répercussions: Dans une perspective d'avenir, il faut clairement enrichir les bases de données actuelles afin d'accroître le potentiel des données sur les SSP au Canada. Les données sont nécessaires pour faciliter la compréhension des extrants et des résultats des SSP et pour faire des associations entre les divers aspects des SSP. Un engagement envers une stratégie pour la collecte de données détaillées et envers un système d'information est indispensable dans toutes les provinces et tous les territoires canadiens afin de renseigner l'élaboration et la planification des politiques, dévaluer les initiatives de restructuration des SSP et de satisfaire aux attentes des Canadiens en matière d'obligation redditionnelle.

\footnotetext{
7 anadians have expressed concern about access to and Quality of primary healthcare (PHC), as well as support for changes to PHC including collaborative team-based care (Pollara 2005; Watson and Krueger 2005).
} They have also indicated concern for accountability and a desire for increased transparency and reporting on the results of healthcare expenditures and renewal initiatives (Pollara 2003). In response, federal, provincial and territorial governments have made 
substantive, multi-year investments in healthcare reform and have committed to regular reporting on health system performance and progress towards system renewal in the First Ministers' communiqué on health (Canadian Intergovernmental Conference Secretariat 2000), the Primary Health Care Transition Fund (Health Canada 2000), the First Ministers' Health Accord (Health Canada 2003) and the First Ministers' 10-Year Plan to Strengthen Health Care (Health Canada 2004).

Despite investments in PHC renewal and a commitment to increased public reporting, a performance measurement and accountability framework for this sector has not been established in Canada. Such a framework is needed, along with population-based data, to support policy and management initiatives to improve quality and report on progress resulting from renewal initiatives. The creation of information systems to support this agenda should leverage existing data collection, monitoring and reporting and be supplemented with new data sources and systems that fill information gaps in priority areas.

In response to this challenge, researchers at the Centre for Health Services and Policy Research developed the Results-Based Logic Model as a guide for developing a population-based PHC information system and evaluating PHC (Watson et al. 2004). Concurrently, we undertook a review of PHC performance measurement in Canada to identify existing data sources for PHC reporting. The purpose of this paper is to illustrate how existing population-based administrative and survey data can be used to describe dimensions of PHC. We identify gaps in existing data and priorities that should be addressed for PHC reporting, and offer suggestions to address these gaps. This report will be of interest to those responsible for planning future data requirements and information systems for $\mathrm{PHC}$, along with those undertaking $\mathrm{PHC}$ evaluation and research across Canada.

\section{What Did We Do?}

Our work was guided by the Results-Based Logic Model for PHC described earlier in this special issue of Healthcare Policy (Watson et al. 2009a; see page 33). The Results-Based Logic Model was developed using the approach of the Treasury Board of Canada to performance management and accountability reporting. This approach focuses on measuring and reporting outcomes throughout the life cycle of a policy, program or initiative and integrating strategy, people, processes and measurement to improve decision-making and drive change. Beginning with the creation of a resultsbased logic model, this approach uses indicators to assess performance along with analyses to link variation in resource inputs and activities performed to changes in outputs and outcomes achieved (Treasury Board of Canada 2001).

We used the Results-Based Logic Model to guide our review of population-based data sources and performance measures in Canada. To identify performance indicators 
that are currently available for dimensions of the Results-Based Logic Model, we examined existing population-based data sources, including surveys of citizens, surveys of providers and reports describing the use of administrative data. This information illustrates the potential to use existing data sources to measure PHC inputs, activities, outputs and outcomes. The data sources and performance measures identified in this paper are not exhaustive; rather, the information is intended to illustrate availability from existing robust and accepted data sources. Similarly, this information is not intended to describe the "best" or preferred performance measures. Our full report, including more than 130 performance indicators, is available on the website of the Centre for Health Services and Policy Research (Broemeling et al. 2006).

This information was then used to identify gaps in current data available to report on PHC dimensions and renewal initiatives. We also used results from work, as well as consultations with citizens, to identify priorities for information and make recommendations to guide planning for future data collection and PHC information systems (see Watson et al. 2009a; page 35 in this special issue).

\section{What Did We Learn?}

Table 1 provides examples of measures that are available or can be derived from existing survey and administrative data sources. Measures of intermediate and final outcomes are not described in Table 1 because the attribution of these outcomes to PHC is limited by the impact of external factors.

TABLE 1. PHC performance measures using existing population-based data sources

\begin{tabular}{|l|l|l|}
\hline \multicolumn{2}{|l|}{ Dimension } & Administrative Data \\
\hline Population characteristics \& contexts & $\begin{array}{l}\text { Population estimates, distribution } \\
\text { by age, gender, geography: 200 I } \\
\text { Census of Canada (Statistics Canada } \\
\text { 2006a) }\end{array}$ & $\begin{array}{l}\text { Vital statistics: births, deaths (British } \\
\text { Columbia Ministry of Health Vital } \\
\text { Statistics Agency 2006) }\end{array}$ \\
\hline Demographics & $\begin{array}{l}\text { Chronic condition prevalence rates: } \\
\text { self-reported chronic conditions } \\
\text {-Canadian Community Health } \\
\text { (CCHS) Survey, Cycle 3.I (Statistics } \\
\text { Canada 2006b), Q0I I-Q22I }\end{array}$ & $\begin{array}{l}\text { Chronic condition treatment } \\
\text { prevalence rates: diagnoses } \\
\text { from medical, hospital and other } \\
\text { administrative sources (Broemeling } \\
\text { et al. 2005) }\end{array}$ \\
\hline Health Behaviours & $\begin{array}{l}\text { Health behaviours, changes to } \\
\text { improve health: CCHS Cycle 3. I, } \\
\text { ClH_QI to CIH_Q8 }\end{array}$ & \\
\hline Social, Economic, Cultural, Physical, \\
Policy/Legislative Contexts & $\begin{array}{l}\text { Income, labour force participation, } \\
\text { education, ethnicity: 200I Census } \\
\text { of Canada }\end{array}$ & $\begin{array}{l}\text { Risk indices: children at risk (BC } \\
\text { STATS 2009) }\end{array}$ \\
\hline
\end{tabular}


Anne-Marie Broemeling et al.

TABLE 1. Continued

\begin{tabular}{|c|c|c|}
\hline \multicolumn{3}{|l|}{ Inputs } \\
\hline Health Human Resources & $\begin{array}{l}\text { GP/FP age, sex distribution: } \\
\text { National Physician Survey (NPS) } \\
\text { (College of Family Physicians of } \\
\text { Canada 2004), Q31, Q32 }\end{array}$ & $\begin{array}{l}\text { GP/FP-to-specialist ratio (College } \\
\text { registration data) } \\
\text { PHC nurse-to-PHC physician ratio } \\
\text { (Wong et al. 2006) }\end{array}$ \\
\hline Material Resources & $\begin{array}{l}\text { Internet access in main patient care } \\
\text { area: NPS 2004, Q22 }\end{array}$ & $\begin{array}{l}\text { Hospital beds (Annual Return of } \\
\text { Healthcare Facilities) }\end{array}$ \\
\hline Fiscal Resources & & $\begin{array}{l}\text { Public sector expenditures } \\
(\mathrm{ClHI} 2005 \mathrm{a})\end{array}$ \\
\hline \multicolumn{3}{|l|}{ Activities } \\
\hline Policy/Governance Level & $\begin{array}{l}\text { Remuneration method: FFS, } \\
\text { capitation, salary, blended, others - } \\
\text { NPS 2004, QI4 }\end{array}$ & $\begin{array}{l}\text { Distribution of physician } \\
\text { expenditures by physician payment } \\
\text { category: FFS, salary, sessional, } \\
\text { capitation, others (CIHI 2006) }\end{array}$ \\
\hline Management Level & $\begin{array}{l}\text { GP/FP patient care setting: solo, } \\
\text { group, practice network, other: NPS } \\
2004, \text { Q3a } \\
\text { Nurse or other healthcare } \\
\text { professional that is regularly involved } \\
\text { in your care: } 2008 \text { CSE-PHC, } \\
\text { Question HU_Q0 I, Q02 }\end{array}$ & $\begin{array}{l}\text { Primary care physicians in group } \\
\text { practice (Reid et al. 2003) }\end{array}$ \\
\hline Clinical Level & $\begin{array}{l}\text { GP/FP participation in maternity, } \\
\text { newborn care: NPS 2004, Q9 }\end{array}$ & $\begin{array}{l}\text { GP/FP provision of non-office care: } \\
\text { emergency, intrapartum, nursing } \\
\text { home, house call, others (Chan and } \\
\text { Ovens 2002) }\end{array}$ \\
\hline \multicolumn{3}{|l|}{ Outputs } \\
\hline Volume and Type & $\begin{array}{l}\text { Contacts with health providers: } \\
\text { CCHS Cycle 3.I, HC_Q02, Q03 } \\
\text { Patient visits/week, exc. call: NPS } \\
\text { 2004, Q_C6 }\end{array}$ & $\begin{array}{l}\text { GP/FP or PHC visits and visit rates/ } \\
\text { population (Watson et al. 2005) }\end{array}$ \\
\hline Accessibility & $\begin{array}{l}\text { Difficulty obtaining routine or } \\
\text { ongoing health services: derived } \\
\text { from CCHS (see Sanmartin et al. } \\
\text { 2004) } \\
\text { Length and acceptability of wait for } \\
\text { routine or ongoing care, as well as } \\
\text { immediate care for a minor health } \\
\text { problem: } 2008 \text { CSE-PHC Question } \\
\text { AC_QI0, QII, Q I6, QI7 }\end{array}$ & $\begin{array}{l}\text { Utilization rates (i.e., realized access) } \\
\text { (Menec et al. 2002) }\end{array}$ \\
\hline Continuity & $\begin{array}{l}\text { Proportion of population who report } \\
\text { having a regular family doctor: } \\
\text { derived from CCHS (see Sanmartin } \\
\text { et al. 2004) } \\
\text { How long have you been seeing or } \\
\text { going to this primary care provider: } \\
2008 \text { CSE-PHC Question HU_Q03 }\end{array}$ & $\begin{array}{l}\text { Relational continuity: usual care } \\
\text { provider, preponderance of care } \\
\text { (Reid et al. 2003) }\end{array}$ \\
\hline
\end{tabular}


TABLE 1. Continued

\begin{tabular}{|c|c|c|}
\hline Comprehensiveness & 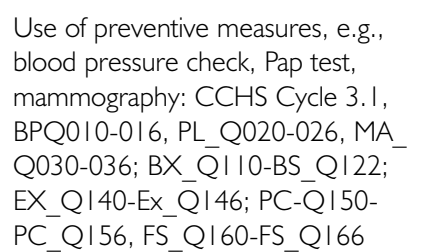 & $\begin{array}{l}\text { Use of primary prevention (e.g., } \\
\text { immunization) and secondary } \\
\text { prevention (screening) services (Lix } \\
\text { et al. 2005) }\end{array}$ \\
\hline Coordination of Care & $\begin{array}{l}\text { How often does your primary care } \\
\text { provider help you coordinate the } \\
\text { services you receive from other } \\
\text { doctors and places when you } \\
\text { need it: } 2008 \text { CSE-PHC Question } \\
\text { HU_Q05 }\end{array}$ & \\
\hline Interpersonal Communication & $\begin{array}{l}\text { In the past } 12 \text { months, how often } \\
\text { did your family physician (or general } \\
\text { practitioner) explain your test results } \\
\text { in a way that you could understand: } \\
2008 \text { CSE-PHC Question EP Q0 I }\end{array}$ & \\
\hline Technical Effectiveness & $\begin{array}{l}\text { In the past } 12 \text { months, did you get } \\
\text { the following tests or measures to } \\
\text { monitor your condition: } 2008 \text { CSE- } \\
\text { PHC Question CC_Q02 }\end{array}$ & $\begin{array}{l}\text { Chronic disease patients: receipt } \\
\text { of recommended care (Katz et al. } \\
\text { 2004) }\end{array}$ \\
\hline \multicolumn{3}{|l|}{ Immediate outcomes } \\
\hline $\begin{array}{l}\text { Maintain or Improve Work Life of } \\
\text { PHC Workforce }\end{array}$ & $\begin{array}{l}\text { GP/FP satisfaction with professional } \\
\text { life: NPS 2004, Q20 }\end{array}$ & \\
\hline $\begin{array}{l}\text { Increased Knowledge about Health } \\
\text { and Healthcare among Population }\end{array}$ & $\begin{array}{l}\text { Changes in risk behaviours: CCHS } \\
\text { Cycle 3. I, ClH_QI to CIH_Q8 } \\
\text { Knowledge about each prescribed } \\
\text { medication: } 2007 \text { CSE-PHC } \\
\text { Question J2 }\end{array}$ & \\
\hline \multicolumn{3}{|l|}{$\begin{array}{l}\text { Reduced Risk, Duration and Effects } \\
\text { of Acute/Episodic Health Conditions }\end{array}$} \\
\hline $\begin{array}{l}\text { Reduced Risk and Effects of } \\
\text { Continuing Health Conditions }\end{array}$ & & $\begin{array}{l}\text { Hospitalization rates/readmissions } \\
\text { to hospital for specific chronic } \\
\text { conditions (CIHI 2005b) }\end{array}$ \\
\hline
\end{tabular}

\section{Population characteristics and contexts}

Population characteristics include health status, behavioural, psycho-social and social support measures and health-related attitudes and preferences. Contextual factors such as social cohesion, social capital and income disparity, and policy and legislative contexts also influence health, patterns of use and delivery of PHC services. A number of population and contextual measures are available or can be derived from existing data sources. Administrative data from provincial medical services plans, vital statistics and program utilization files can be used to describe populations, morbidity, treatment 
prevalence rates for chronic health conditions and mortality. Survey data, including the Canadian Community Health Survey (CCHS) (Statistics Canada 2006b), also provide such important information on population characteristics as self-rated health, disability, activity restrictions, self-reported chronic health conditions, behavioural risks and medical interventions.

\section{PHC inputs}

Human, material and fiscal resources are the inputs that PHC systems rely on to carry out activities, deliver care and achieve results. Health human resources input measures are available both from provincial administrative data sources (provincial colleges of physicians and surgeons registrations and colleges of registered nurses, provincial medical services plans) and from national databases such as the National Physician Database. Survey data sources include such measures as intention to retire and plans to move during the coming year from the National Physician Survey (NPS). Material inputs (e.g., information systems, electronic health records) and financial inputs are also available from administrative and survey data sources.

\section{PHC activities}

$\mathrm{PHC}$ activities describe the work processes undertaken in preparation for delivery of PHC products and services. Activities support the production of outputs and the achievement of outcomes. Three levels of activities are identified: policy and governance, healthcare management and clinical. Policy and governance measures include financing and funding of services. Funding information is currently collected from provincial medical payment administrative data; financing information could be, but is not currently, collected from patient surveys.

Healthcare management activities include decisions about the degree to which practices include interdisciplinary teams or offer services 24 hours a day, seven days a week. Data relating to practice settings and organization are available from the NPS (CFPC 2008). Information about the degree to which patients receive PHC from multidisciplinary teams could be obtained from population surveys, such as the Canadian Survey of Experiences with Primary Health Care (CSE-PHC) which was conducted in 2007 and 2008 (Statistics Canada 2009). Clinical-level activities and decisions can also be measured using existing data sources. For example, physician participation in delivery of maternity care is available from NPS data. Many healthcare management and clinical activity measures focus on physician data sources; less information is available for other providers. 


\section{PHC outputs}

Outputs are the services and products that result from PHC activities: that is, the services delivered by $\mathrm{PHC}$ providers and received by patients. The volume and type of PHC services used by the population overall and by population subgroups can be described using such measures as annual check-ups, screening tests and physician visits for mental health conditions with information from both administrative and survey data. Administrative data sources quantify the number and type of visits covered by publicly funded services, while survey data describe service use from patient and provider perspectives. The 2008 CSE-PHC was conducted by Statistics Canada and designed to offer national and provincial-level estimates regarding the types of services that adults receive (e.g., health promotion, disease prevention) as well as the places they visit for that care (e.g., walk-in clinics).

Qualities of PHC outputs describe the distinctive features of PHC - firstcontact accessibility, comprehensiveness of services, continuity, cultural sensitivity, interpersonal communication, respectfulness, technical quality of clinical care and so on. Selected qualities of PHC outputs can be described using existing data sources. Accessibility can be reported using both survey and administrative data. Surveys such as the CCHS (Statistics Canada 2006b) include perceptions of accessibility and barriers to care, availability of services when needed, convenience of PHC services and degree to which there is unmet need. The 2008 CSE-PHC (Statistics Canada 2009) includes information on wait times and acceptability of those wait times for routine and ongoing care as well as immediate care for minor health problems. Administrative data provide measures of realized access such as use of services.

Relational continuity of care can be assessed using existing CCHS data from patients (e.g., respondents report having a regular medical doctor) and CSE-PHC data (e.g., how long have you been receiving care from your regular primary care provider), while administrative data have been used to derive continuity of care indices such as usual care provider or sequential continuity of care. Measures of informational and management continuity are generally not available from administrative data sources and require either survey or clinical information to assess (Reid et al. 2003). The $\mathrm{CCHS}$ does not currently include questions to assess patient experiences of $\mathrm{PHC}$ continuity of care.

Comprehensiveness measures describe the span of services provided in PHC, from health promotion and disease prevention through acute episodic care, ongoing chronic care and end-of-life care. Measures of comprehensiveness, such as the provision of primary or secondary preventive services, provider activity and referrals to specialist and other providers, are available using NPS survey data, as well as administrative data from provincial medical services plans. The CSE-PHC does not include questions to assess receipt of a comprehensive array of health promotion, disease 
prevention and curative healthcare services from a patient perspective but it does ask respondents if they receive the full range of services they need.

Coordination, another key attribute of PHC, cannot be assessed using administrative data and must rely on survey data. While co-occurrence of services can be identified using linked administrative data (e.g., post-acute use of home care services), it is not clear whether services were actually coordinated with shared provider information and shared care management. Interpersonal communication describes providerpatient communication, shared decision-making and interpersonal style of care, and reflects the degree to which providers offer patient-centred care (Watson et al. 2004). Measures of interpersonal communication cannot be assessed using administrative data, but the CSE-PHC includes a number of items intended to measure coordination and interpersonal communication.

Finally, effectiveness of care or technical effectiveness reflects the degree to which care is consistent with evidence and knowledge and there is high consensus on the importance of this type of information to drive quality improvement (Barnsley et al. 2005). To a limited extent, administrative data can be used to assess technical effectiveness by comparing actual care provided to patients to that recommended; that is, comparing the reported use and frequency of tests, procedures and medications compared with evidence-based guidelines. Measures of technical effectiveness are not currently part of the CCHS, but a module to assess the degree to which people with diabetes reported receiving recommended laboratory tests and procedures was included in the CCHS in 2005. This module was optional, and only six jurisdictions funded data collection in their regions. More recent modules of the CCHS are being designed to measure technical quality for other chronic conditions and the CSE-PHC includes a number of items intended to measure this quality of PHC services.

\section{Primary healthcare outcomes}

PHC outcomes are the result of inputs, activities and outputs, with immediate outcomes being most attributable to PHC.

\section{IMMEDIATE OUTCOMES}

Immediate outcomes describe increased knowledge about health and healthcare among the population, reduced risk, duration and effects of acute and episodic conditions, reduced risk and effects of continuing health conditions, and maintenance or improvement of the work life of the PHC workforce (Watson et al. 2004). Perhaps the best information to assess $\mathrm{PHC}$ immediate outcomes from the provider perspective is to assess job satisfaction and work life measures which are available from existing survey data such as the NPS (for physicians). The other PHC immediate out- 
comes are best measured from the perspective of patients and using longitudinal data. The CSE-PHC does offer some cross sectional data regarding Canadians' knowledge about their health and care management which can be used as a basis for performance indicators and that survey offers data on PHC activities and outputs to support attribution (causal) analyses.

Performance measures for reduced risk and effects of chronic health conditions are best measured from the perspective of patients and using longitudinal data. The CSE-PHC does offer some cross sectional data in this regard, but population-based administrative data are not readily available. While administrative data have been used to measure receipt of recommended care for patients with diabetes (technical effectiveness: PHC output), there are few jurisdictions that have administrative data which include the results of laboratory work (e.g., cholesterol or hemoglobin A1c levels) or diagnostic procedures (e.g., blood pressure) that can be used to measure the effects of care for chronic health conditions such as diabetes. Where such administrative data capacity exists, there is little capacity to link these data to information about PHC inputs, activities and outputs.

\section{INTERMEDIATE OUTCOMES}

Intermediate outcomes include outcomes on which PHC is expected to have an impact, albeit with less control: appropriateness of provider and place, healthcare system efficiency, acceptability and equity (Watson et al. 2004). Measures for acceptability and appropriateness of place are available from survey data, including patient perspectives (CCHS and CSE-PHC) and physician perspectives (NPS). On the other hand, existing administrative data have been used to measure emergency department and hospital use (Cree et al. 2006) and ambulatory care sensitive (ACS) admissions to hospital (CIHI 2005b).

Canadian researchers have had to be creative in measuring PHC efficiency related to differences in technical effectiveness of specialists and general/family practitioners in the delivery of chronic disease management, because there are cost differences associated with variations in physician mix (Shah et al. 2003) or work to assess equity and efficiency in general/family practitioner, nursing, emergency department and home care services relative to the health status of populations (Watson et al. 2005).

\section{FINAL OUTCOMES}

Final outcomes include a sustainable healthcare system, improved/maintained individual health and functioning, and improved level and distribution of population health and wellness (Watson et al. 2004). The complex interplay of PHC, other system factors and variations in population contexts limit the extent to which final outcomes can be attributed to PHC. The outcome of a sustainable healthcare system reflects 
expectations that PHC is a key lever to manage inputs, costs and efficiency of the healthcare system. Evidence from other jurisdictions suggests that healthcare systems with strong PHC have lower overall costs than those that do not (Starfield and Shi 2002). However, there are few assessments of sustainability of the PHC sector; some explore the impact of temporal trends at the population level on future sustainability (Watson et al. 2007). In Canada and elsewhere, researchers have used area-level measures of PHC to study the influence of the PHC sector on the health of populations, healthcare and health status (Pierard 2009; Shi et al. 2003). For all intermediate outcomes and final outcomes, the challenge is to attribute changes in outcomes to PHC as opposed to other system factors.

\section{What Are the Implications?}

Population-based data are available to describe some dimensions of the ResultsBased Logic Model (Watson, Broemeling et al. 2009) and to evaluate selected aspects of PHC renewal. However, despite availability of these data and the importance of accountability and performance reporting to Canadians, there is little routine monitoring and public reporting for this sector. Such reporting would provide important information for delivering PHC services, planning PHC renewal, monitoring changes in PHC performance and assessing the impact of renewal initiatives. It would also inform the $93 \%$ of Canadians who reported that PHC is of high importance (79\%) or medium importance (14\%) to their future health (Health Canada 2006).

Although data are available to measure some aspects of PHC performance, many input and activity measures focus on physician data and there is less information available for other PHC providers or interdisciplinary teams. Recent studies by our team using administrative data to identify PHC nurses (Wong et al. 2006, 2009; see page 91 in this special issue of Healthcare Policy), and by CIHI and Statistics Canada to survey nurses (Shields et al. 2006), are useful additions to describe nursing's contribution to PHC service delivery.

Moreover, because an increasing proportion of physician services are financed through alternative funding arrangements (CIHI 2006), the availability of administrative data for performance measurement is declining. Two papers in this special issue (Broemeling, Kerluke et al. 2009 and Watson, Peterson et al. 2009) assess the degree to which completeness and accuracy of administrative data are eroding for measurement of provider and population perspectives of $\mathrm{PHC}$ and what can be done so that administrative data can still be used for performance measurement in Canada.

As well, our current ability to assess some qualities of PHC outputs - interpersonal communication, continuity and coordination of care - has been limited; the new CSE-PHC will enhance capacity to measure these dimensions based on individuals' experiences and linkage of that survey to administrative data will enhance capacity to 
measure the impact of variation in these qualities on longer term outcomes such as use of hospitals.

There are notable gaps in existing data to assess the immediate outcomes of PHC, particularly those outcomes that require longitudinal data. Little information is currently available to assess the impact of PHC on the risks, duration and effects of acute and episodic health conditions, or the risks and effects of chronic health conditions. Data are also not readily available to measure the impact of PHC on the immediate outcome of increased knowledge about health and healthcare among the population. It is possible to incorporate this information into surveys or to extract it from electronic data; however, if the information is to be used to improve the quality of PHC, it must be linkable to information on outputs (at a minimum) or, more ideally, to inputs, activities and outputs to support evaluative research and analyses.

Selected intermediate and final outcomes can be assessed with existing data sources, but these measures are neither comprehensive nor easily linked to support the attribution of PHC inputs, activities and outputs to PHC outcomes. Many external factors, in addition to PHC, contribute to these intermediate and final health outcomes, limiting our ability to assess PHC's contribution. Longitudinal data sources linking patients and providers are needed if we are to assess the impact of PHC on individual and population outcomes and health improvements over time, as well as threats to, and opportunities to support, healthcare system sustainability.

A full evaluation of PHC renewal will require a comprehensive data collection strategy that accounts for the dimensions of PHC and the links among PHC dimensions. For example, do interdisciplinary teams improve access to recommended care for those with chronic health conditions? And how do interdisciplinary teams working to improve access to care influence the relational continuity of care between patients and providers?

A comprehensive data collection strategy would have to provide population-based, multi-level data for individual residents, patients, providers, clinics and organizations. Such an information system must support linkage of individual patients to providers, clinics and other healthcare organizations in order to attribute changes over time to PHC services and renewal initiatives. Longitudinal data are required to support temporal analyses of factors contributing to the health of Canadians. Finally, comprehensive data are needed across the PHC dimensions, from contexts to inputs, activities and outputs to outcomes, as well as the linkages among each of these dimensions.

\section{Recommendations}

We conclude that there is population-based data capacity to begin to describe the population characteristics, contexts, inputs and activities of PHC, but insufficient data to describe outputs and outcomes and to attribute outcomes to this sector. Focusing on data sources to measure immediate outcomes for PHC, along with the linkages 
among contexts, inputs, activities, outputs and outcomes, will be an important priority in supporting local, provincial and national evaluation of $\mathrm{PHC}$ renewal.

We recommend commitment to a comprehensive PHC data collection strategy and information system. In the short term, priorities should be established as follows:

1. Establish standardized data collection strategies across jurisdictions to address the completeness and accuracy of traditional administrative data holdings for general and family practitioners. This action is required to address the erosion in administrative data resulting from the increase in alternative payments and PHC services delivered via such arrangements.

2. Implement a regular survey of Canadians to track the unique and distinguishing features of PHC, such as type and volume of health promotion, disease prevention and curative services received, as well as patient experiences with continuity, coordination of care and interpersonal communication. Such data could be used to assess the degree of variation in volume, type and qualities of outputs with selfreported outcomes such as use of other healthcare services. While the CSE-PHC was conducted in 2007 and 2008, there are no plans dedicated towards ensuring that it be conducted on an annual or biannual routine basis.

3. Implement studies to assess policyrelevant activities such as impact of the introduction of multidisciplinary teams on PHC outputs and outcomes. Ad hoc studies are required because administrative and survey data cannot be linked to information about PHC organizational design.

In the medium to longer term:

There is remarkable potential to develop comprehensive, longitudinal and multi-layered data for primary healthcare that supports performance measurement and research at the population or system level

4. Ensure that electronic health records are designed and implemented so that data for PHC outputs and outcomes are complete and reliable, and can be routinely linked to information about PHC inputs, management and clinical-level activities, population contextual factors and use of other healthcare services. A comprehensive information system would support analyses to inform quality improvement efforts and enable public reporting.

There is remarkable potential to develop comprehensive, longitudinal and multilayered data for PHC that supports performance measurement and research at the population or system level and, at the same time, supports providers with information on care delivery to inform quality improvement efforts and planning for future needs. 
We recommend the development of a Canadian PHC data collection strategy that builds on the unique qualities and strengths of population-based data. A comprehensive, collaborative PHC data collection strategy, combined with a common evaluation framework, would provide the necessary building blocks for PHC evaluation and performance measurement. The final paper in this issue (Watson 2009) offers a roadmap of options for new information systems so as to address existing gaps in high priority information about PHC in Canada. Commitment to this work is necessary if we are to meet the expectations of Canadians.

\section{ACKNOWLEDGEMENTS}

The British Columbia Ministry of Health Services provided funding for this project as well as some of the funding for the special issue in which this article is published. Dr. Wong was supported by a career award from the National Institute of Aging (NIA) (444918-31259) and a scholar award from the Michael Smith Foundation for Health Research (MSFHR). Conclusions are those of the authors and reflect no official endorsement by our funders. We would like to acknowledge the contributions of Dr. Rob Reid to our original report on this topic.

Correspondence may be directed to: Dr. Anne-Marie Broemeling, Director, Information Support and Research, Interior Health Authority, 104-1815 Kirschner Road, Kelowna, BC V1Y 4N7; tel.: 250-870-4649; fax 250-870-4605; e-mail: annemarie.broemeling@interiorhealth.ca.

\section{REFERENCES}

Barnsley, J., W. Berta, R. Cockerill, J. MacPhail and E. Vayda. 2005. “Identifying Performance Indicators for Family Practice. Assessing Levels of Consensus." Canadian Family Physician 51: 700-01.

British Columbia. 2009. BC Stats: BC Regional Socio-economic Profiles and Indices. Victoria, BC: Province of British Columbia. Accessed March 23, 2009. <http://www.bcstats.gov.bc.ca/DATA/ sep/i_lha/lha_main.asp $>$.

British Columbia. 2006. Ministry of Health Vital Statistics Agency: Selected Vital Statistics and Health Status Indicators, Annual Report 2006. Victoria, BC: Province of British Columbia. Accessed March 23, 2009. <http://www.vs.gov.bc.ca/stats/annual/2006/pdf/ann06.pdf>

Broemeling, A.-M., K. Kerluke, C. Black, S. Peterson, A. MacDonald and R. McKendry. 2009. “Developing and Maintaining a Population Research Registry to Support Primary Healthcare Research." Healthcare Policy 5(Sp): 65-76.

Broemeling, A.-M., D. Watson and C. Black. 2005. Chronic Conditions and Co-morbidity among Residents of British Columbia. Vancouver: Centre for Health Services and Policy Research. Retrieved January 7, 2009. <http://www.chspr.ubc.ca/node/109>. 
Broemeling, A.-M., D.E. Watson, C. Black and R.J. Reid. 2006. Measuring the Performance of Primary Health Care: Existing Capacity and Future Information Needs. Vancouver: Centre for Health Services and Policy Research. Retrieved January 7, 2009. <http://www.chspr.ubc.ca/ research/phc/measuring $>$.

Canadian Institute for Health Information (CIHI). 2005a. Health Care in Canada 2005. Ottawa: Author.

Canadian Institute for Health Information (CIHI). 2005b. Hospital Trends in Canada. Results of a Project to Create a Historical Series of Statistical and Financial Data for Canadian Hospitals Over Twenty-Seven Years. Ottawa: Author.

Canadian Institute for Health Information (CIHI). 2006. The Status of Alternative Payment Programs for Physicians in Canada, 2003-2004 and Preliminary Information for 2004-2005.

Ottawa: Author.

Canadian Intergovernmental Conference Secretariat. 2000. First Ministers' Meeting Communiqué on Health. Retrieved January 7, 2009. <http://www.scics.gc.ca/cinfo00/800038004_e.html>.

Chan, B.T. and H.J. Ovens. 2002."Frequent Users of Emergency Departments. Do They Also Use Family Physicians' Services?” Canadian Family Physician 48: 1654-60.

College of Family Physicians of Canada (CFPC). 2004. National Physician Survey 2004. Retrieved January 7, 2009. <http://www.nationalphysiciansurvey.ca/nps/2004_Survey/downloadcenter2004-e.asp $>$.

College of Family Physicians of Canada (CFPC). 2008 (October 23). National Physician Survey. Retrieved January 7, 2009. <http://www.nationalphysiciansurvey.ca/nps>.

Cree, M., N.R. Bell, D. Johnson and K.C. Carriere. 2006. "Increased Continuity of Care Associated with Decreased Hospital Care and Emergency Department Visits for Patients with Asthma." Disease Management 9(1): 63-71.

Health Canada. 2000. Primary Health Care Transition Fund. Retrieved January 7, 2009. <http:// www.hc-sc.gc.ca/hcs-sss/prim/phctf-fassp/index_e.html>.

Health Canada. 2003. First Ministers' Accord on Health Care Renewal. Retrieved January 7, 2009. <http://www.hc-sc.gc.ca/hcs-sss/delivery-prestation/fptcollab/2003accord/index-eng.php>. Health Canada. 2004. First Ministers' Meeting on the Future of Healthcare. Retrieved January 7 , 2009. <http://www.hc-sc.gc.ca/hcs-sss/delivery-prestation/fptcollab/2004-fmm-rpm/index_e. html $>$.

Health Canada. 2006 (September 28). National Primary Health Care Awareness Strategy. Retrieved January 7, 2009. <http://www.health-policy-branch.hc-sc.gc.ca/hpb/phctf/pchtf.nsf/WebFactShe et_E/0034? OpenDocument $>$.

Health Council of Canada. 2007. Why Health Care Renewal Matters: Learning from Canadians with Chronic Health Conditions. Toronto: Health Council. Retrieved March 23, 2009. <http:// healthcouncilcanada.ca/docs/rpts/2007/outcomes2/Outcomes2FINAL.pdf>

Katz, A., C. DeCoster, B. Bogdanovic, R.A. Soodeen and D. Chateau. 2004. Using Administrative Data to Develop Indicators of Quality in Family Practice. Winnipeg: Manitoba Centre for Health Policy.

Lix, L., G. Finlayson, M. Yogendran, R. Bond, J. Bodnarchuk and R.A. Soodeen. 2005. Primary Prevention: An Examination of Data Capabilities in Manitoba. Winnipeg: Manitoba Centre for Health Policy. 
Menec, V.H., L. MacWilliam, R.A. Soodeen and L. Mitchell. 2002. The Health and Healthcare Use of Manitoba's Seniors: Have They Changed Over Time? Winnipeg: Manitoba Centre for Health Policy.

Pierard, E. 2009. The Effect of Physician Supply on Health Status as Measured in the National Population Health Survey. Waterloo Economic Series. Working Paper \#09-01. University of Waterloo.

Pollara Research Inc. 2003. Health Care in Canada Survey, 2003. Retrieved July 10, 2006. <http:// www.hcic-sssc.ca/index_e.asp >.

Pollara Research Inc. 2005. Health Care in Canada Survey, 2005. Toronto, ON: Pollara Research Inc. Retrieved July 10, 2006. <http://www.hcic-sssc.ca/index_e.asp>.

Reid, R.J., M.L. Barer, R. McKendry, K.M. McGrail, B. Prosser, B. Green, R.G. Evans, E. Goldner, C. Hertzman and S.B. Sheps. 2003. Patient-Focused Care Over Time: Issues Related to Measurement, Prevalence and Strategies for Improvement among Patient Populations. Ottawa: Canadian Health Services Research Foundation.

Sanmartin, C., F. Gendron, J.M. Berthelot and K. Murphy. 2004. Access to Health Care Services in Canada, 2003. Ottawa: Statistics Canada. Catalogue no. 82-575-XIE.

Shah, B.R., M. Mamdani and A. Kopp. 2003. “Drug Use in Older People with Diabetes.” In J.E. Hux, G.L. Booth, P.M. Slaughter and A. Laupacis, eds., Diabetes in Ontario: An ICES Practice Atlas. Toronto: Institute of Clinical Evaluative Sciences.

Shi, L., J. Macinko, B. Starfield, J. Wulu, J. Regan and R. Politzer. 2003.“The Relationship between Primary Care, Income Equality and Mortality in the United States, 1980-1995." Journal of the American Board of Family Practice 16: 412-22.

Shields, M., K. Wilkins, Health Canada, Statistics Canada and Canadian Institute for Health Information. 2006. Findings from the 2005 National Survey of the Work and Health of Nurses. Ottawa: Health Canada/CIHI.

Starfield, B. and L. Shi. 2002. "Policy-Relevant Determinants of Health: An International Perspective." Health Policy 60(3): 201-18.

Statistics Canada. 2006a. 2001 Census of Canada. Retrieved January 7, 2009. <http://www12. statcan.ca/english/census01/home/index.cfm>.

Statistics Canada. 2006b. Population Health Surveys: Canadian Community Health Survey. Retrieved January 7, 2009. <http://www.statcan.ca/english/concepts/hs/index.htm>.

Statistics Canada. 2009. Canadian Survey of Experiences with Primary Health Care. Retrieved April 2, 2009. < http://www.statcan.gc.ca/cgi-bin/imdb/p2SV.pl?Function=getSurvey\&SDDS= 5138\&lang $=$ en $\& \mathrm{db}=\mathrm{imdb} \& \mathrm{adm}=8 \& \mathrm{dis}=2>$

Treasury Board of Canada. 2001. Guide to the Development of Results-Based Management and Accountability Frameworks. Retrieved January 7, 2009. <http://www.tbs-sct.gc.ca/eval/pubs/ RMAF-CGRR/rmafcgrr05_e.asp >.

Watson, D.E., A.-M. Broemeling, R.J. Reid and C. Black. 2004. A Results-Based Logic Model for Primary Health Care. Laying an Evidence-Based Foundation to Guide Performance Measurement, Monitoring and Evaluation. Vancouver: Centre for Health Services and Policy Research. Retrieved January 9, 2009. <http://www.chspr.ubc.ca/research/phc/logicmodel >.

Watson, D.E., A.-M. Broemeling and S.T. Wong. 2009. "A Results-Based Logic Model for Primary Healthcare: A Conceptual Foundation for Population-Based Information Systems." Healthcare Policy 5(Sp): 33-46. 
Watson, D.E., M. Hillmer, F. Prebtani and K. Leeb. 2007."Why Healthcare Renewal Matters: Lessons From Diabetes." Healthcare Papers 7(4): 54-60.

Watson, D.E. and H. Krueger. 2005. Primary Health Care Experiences and Preferences: Research Highlights. Vancouver: Centre for Health Services and Policy Research. Retrieved January 7, 2009. $<$ http://www.chspr.ubc.ca/node/90>.

Watson, D.E., H. Krueger, D. Mooney and C. Black. 2005. Planning for Renewal: Mapping Primary Health Care in British Columbia. Vancouver: Centre for Health Services and Policy Research. Retrieved January 7, 2009. <http://www.chspr.ubc.ca/research/phc/mapping>.

Watson, D.E., S. Peterson, E. Young and B. Bogdanovic. 2009. "Methods to Develop and Maintain a Valid Physician Registry in Evolving Information Environments." Healthcare Policy 5(Sp): 77-90.

Watson, D.E. 2009. “For Discussion: A Roadmap for Population-Based Information Systems to Enhance Primary Healthcare in Canada." Healthcare Policy 5(Sp): 105-20.

Wong, S.T., D.E. Watson, E. Young, D. Mooney and M. MacLeod. 2006. Who Are the Primary Healthcare Registered Nurses in British Columbia? Vancouver: Centre for Health Services and Policy Research. Retrieved January 7, 2009. <http://www.chspr.ubc.ca/research/phc/provider/nurses >.

Wong, S.T., D.E. Watson, E. Young and D. Mooney. 2009. "Supply and Distribution of Primary Healthcare Registered Nurses in British Columbia." Healthcare Policy 5(Sp): 91-104. 